\title{
Assessing health-related quality of life in Japanese children with a chronic condition: validation of the DISABKIDS chronic generic module
}

Hatoko Sasaki ${ }^{1{ }^{*}}$, Naoko Kakee ${ }^{2 \dagger}$, Naho Morisaki ${ }^{3}$, Rintaro Mori ${ }^{4}$, Ulrike Ravens-Sieberer ${ }^{5}$ and Monika Bullinger ${ }^{6}$

\begin{abstract}
Background: This study examined the reliability and validity of the Japanese versions of the DISABKIDS-37 generic modules, a tool for assessing the health-related quality of life (HRQOL) of children and adolescents with a chronic condition.

Methods: The study was conducted using a sample of 123 children/adolescents with a chronic medical condition, aged 8-18 years, and their parents. Focus interviews were performed to ensure content validity after translation. The classical psychometric tests were used to assess reliability and scale intercorrelations. The factor structure was examined with confirmatory factor analysis (CFA). Convergent validity was assessed by the correlation between the total score and the sub-scales of DISABKIDS-37 as well as the total score of KIDSCREEN-10.

Results: Both the children/adolescent and parent versions of the score showed good to high internal consistency, and the test-retest reliability correlations were $r=0.91$ or above. The CFA revealed that the modified models for all domains were better fit than the original 37 item scale model for both self-report and proxy-report. Moderate to high positive correlations were found for the associations within DISABKIDS-37 sub-scales and between the subscales and total score, except for the treatment sub-scale, which correlated weakly with the remaining subscales. The total score of the child-reported version of KIDSCREEN-10 correlated significantly and positively with the total score and all the sub-scales of the child-reported version of DISABKIDS-37 except the Treatment sub-scale in adolescents.
\end{abstract}

Conclusions: The modified models of Japanese version of DISABKIDS generic module were psychometrically robust enough to assess the HRQOL of children with a chronic condition.

Keywords: Children, Adolescents, Chronic conditions, Health-related quality of life, Assessment, Validation

\section{Background}

In 2013 , there were 106,937 children (123,435 including registered patients receiving growth hormone therapy) with a chronic condition who received "Medical Aid for Specific Chronic Diseases of Children" in Japan [1]. The total number of registrations remained above 100,000 for the last five years [2]. Health-related quality of life

\footnotetext{
* Correspondence: hatokos@hotmail.com

${ }^{\dagger}$ Equal contributors

${ }^{1}$ Medical Support Center for Japan Environment and Children's Study (JECS), National Center for Child Health and Development, 2-10-1 Okura, Setagaya, Tokyo 157-8535, Japan

Full list of author information is available at the end of the article
}

(HRQOL) tends to be low in children with chronic conditions in Japan [3-5]. Factors include strains related to the management of the illness, increased frequency of hospital visits, and problems in life at school and at home [6, 7]. HRQOL is widely recognized as an important patient-reported outcome (PRO) in the clinical setting as it is critical for understanding the trajectories of health and illness, impacts of treatment, and issues of non-adherence in children with special health care needs [8]. Using such information, health professionals and teachers may be able to identify the types of intervention

(c) The Author(s). 2018 Open Access This article is distributed under the terms of the Creative Commons Attribution 4.0 International License (http://creativecommons.org/licenses/by/4.0/), which permits unrestricted use, distribution, and reproduction in any medium, provided you give appropriate credit to the original author(s) and the source, provide a link to the Creative Commons license, and indicate if changes were made. The Creative Commons Public Domain Dedication waiver (http://creativecommons.org/publicdomain/zero/1.0/) applies to the data made available in this article, unless otherwise stated. 
or educational support required to respond to children's specific needs and to improve their HRQOL.

Although there is an increasing need for understanding the HRQOL in children and adolescents with a chronic condition in Japan, there are very few self-reported instruments designed to assess HRQOL specifically in this population. The Japanese version of PedsQL [9], KIDSCREEN [10, 11], and Kiddy-KINDLR [12] are available for pediatric HRQOL. The European DISABKIDS project [13] developed a pediatric instrument for measuring the HRQOL of children and adolescents aged 8-18 years with a chronic condition containing chronic generic- and disease-specific modules as well as a 'smiley' version for younger children aged 4-7 years. The development process across seven European countries resulted in cross-culturally valid, chronic, generic- as well as condition-specific DISABKIDS modules for both the selfreported and parent-reported versions. The DISABKIDS smiley measure for assessing HRQOL in younger children aged 4-7 years has already been validated for Japanese children with a chronic condition [14].

In the present study, the authors aimed to provide a Japanese version of the DISABKIDS chronic generic module and examine its reliability and validity for assessing the HRQOL of Japanese children and adolescents.

\section{Methods}

\section{Ethical considerations}

Participating in the pre-test (focus interviews) was voluntary, and written consent was obtained from all participants: verbal consent was obtained from children aged 8-18 years and the written consent form was completed by their parents. Participation in the field test was voluntary and written consent was forfeited since the survey was fully anonymized. All participants were assured of the anonymity and confidentiality of the data. The pre-test and field-test were approved by the Ethical Review Board of the National Center for Child Health and Development (NCCHD) in Tokyo, Japan on November 1, 2013 and December 27, 2013, respectively.

\section{Participants}

We recruited chronically ill children and adolescents aged 8-18 years (with asthma, dermatitis, respiratory disease, endocrine disease, or collagen disease) and their families as outpatients of the NCCHD in Japan. NCCHD is the only national hospital to encompass the four areas of paediatric, perinatal, obstetric and maternal medicine in Japan. The hospital has 9 medical departments with 470 beds covering main areas in paediatrics and obstetrics. Approximately 1000 outpatients visit the hospital per day. The inclusion criteria for the participants were treatment of the same chronic condition for at least six months, voluntary consent, and regular visits to a doctor. The exclusion criteria were difficulty reading and completing the questionnaire and inability to provide voluntary consent. We aimed at a balanced distribution of gender and age.

\section{Procedure \\ Translation and pre-test (focus interviews)}

Developing the instrument and testing the guidelines of the DISABKIDS group was followed by translating the questionnaire and conducting the pre-test [15]. After revising the forward-back translations, an international exchange with members of the DISABKIDS group was done to evaluate the final forward translation. Focus interviews were conducted with six male and female children (8-12 years old), and six male and female adolescents (13-18 years old), as well as with their parents using the Japanese translation. To test content validity, a researcher (interviewer) asked participants whether 1) each item was easy to understand, 2) any relevant issues were missing, and 3) the response scale agreed with each item, and recorded their answers. This process was done from October to December 2013.

\section{Field-test}

In total, 123 patients and one parent of each child were invited to participate in the survey. Research assistants explained the purpose and procedure. After both child and parent gave their consent, they were asked to answer the questionnaire while they waited to be seen by a doctor. After completing the questionnaire, the participants received a retest questionnaire to be returned by mail two weeks after the first administration.

\section{Instrument}

\section{DISABKIDS chronic generic module 37}

The DISABKIDS Chronic Generic Module is a selfreported and parent-reported 37-item instrument with response options ranging from 'never' to 'always.' The subscales are: Independence, Emotion, Social inclusion, Social exclusion, Physical Limitation, and Treatment. Independence assessed autonomy and the degree to which children were living without impairments caused by their condition. Physical Limitation assessed functional limitations and perceived health status. Emotion addressed worries, concerns, anger, and problems. Social Inclusion dealt with the acceptance of others and positive social relationships whereas Social Exclusion dealt with stigma and the feeling of being left out. Treatment described the emotional impact of taking medication, receiving injections, applying local treatment, etc. [16]. The DISABKIDS Group [16] reported that Cronbach's alpha reliabilities with Independence $(\alpha=0.78)$, Emotion $(\alpha=0.87)$, Social inclusion $(\alpha=0.70)$, Social exclusion $(\alpha$ $=0.75)$, Physical Limitation $(\alpha=0.73)$ and Treatment $(\alpha$ 
$=0.80)$ for child version, and with Independence $(\alpha=0$. $85)$, Emotion $(\alpha=0.90)$, Social inclusion $(\alpha=0.78)$, Social exclusion $(\alpha=0.80)$, Physical Limitation $(\alpha=0.77)$ and Treatment $(\alpha=0.85)$ for proxy version. The test-retest reliability at one month interval with Item intraclass correlation (ICC) with Independence $(\mathrm{ICC}=0.74)$, Emotion $(\mathrm{ICC}=0.82)$, Social inclusion $(\mathrm{ICC}=0.79)$, Social exclusion $(\mathrm{ICC}=0.81)$, Physical Limitation $(\mathrm{ICC}=0.83$ ) and Treatment $(\mathrm{ICC}=0.71)$ dimensions in child scores and Independence ( $\mathrm{ICC}=0.77$ ), Emotion ( $\mathrm{ICC}=0.76$ ), Social inclusion (ICC $=0.77)$, Social exclusion $(\mathrm{ICC}=0.83)$, Physical Limitation $(\mathrm{ICC}=0.80)$ and Treatment $(\mathrm{ICC}=$ 0.73) facets in proxy scores.

\section{KIDSCREEN-10}

The KIDSCREEN-10 [17] is a 10-item, abbreviated version of the original KIDSCREEN-52 [18] using a 7-point scale ranging from never to always, designed to measure the physical, psychological, and social aspects of quality of life in children and adolescents 8 to 18 years of age. Cronbach's alpha reliabilities were 0.82 for the selfreport (8-11 years old: $0.79,12-18$ years old: 0.81$)$ and 0.78 for the proxy report $(8-11$ years old: $0.78,12-$ 18 years old: 0.78$)$. Test-retest reliabilities were 0.70 for the self-report (8-11 years old: $0.64,12-18$ years old: 0 . $69)$ and 0.67 for the proxy report (8-11 years old: 0.64 , 12-18 years old: 0.66$)$. The Japanese version of KIDSCREEN-52 was developed and validated by Nezu et al. [10], who also reported on the reliability and validity of KIDSCREEN-10 [11]. In this study, the KIDSCREEN-10 was administered to test the convergent validity of the DISABKIDS Chronic Generic Module.

\section{Statistical analysis}

All statistical analyses were performed using SPSS version 21.0 (IBM Corporation, USA). The distribution characteristics of each item were checked by the means and standard deviations (SDs). Skewness and the percentage frequency of the minimum and maximum values were calculated as the ceiling and floor effects, respectively. Internal consistency of the scales was tested using Cronbach's alpha as well as Guttman split-half reliability. The item-subtotal correlation of Cronbach's alpha and Cronbach's alpha if item is deleted were calculated separately for the self-reported and parent-reported versions. Items with item-subtotal correlation < 0.3 [19], and within each subscale the items whose deletion would lead to an increase of alpha of at least 0.02 were candidate for deletion [13]. ICC were computed to assess the level of concordance between the self- and parentreported scores. Test-retest reliability was assessed at a two-week interval using ICC to detect any systematic errors [20].
The factor structure of the Japanese DISABKIDS Chronic Generic Module was examined with confirmatory factor analysis (CFA) using AMOS version 21.0 (IBM Corporation, USA). As the original scale development and pilot study [21] performed the CFA separately for the Mental, Social and Physical in order to assess item loadings on each of these domains, we followed this approach. The values of goodness of fit (GFI) above 0.90 are common in adequate models, and values below 0.90 indicate poorly fit models. The comparative fit index (CFI) is considered good fit at values near one and poor fit at values below 0.90. The Root Mean Square Error of Approximation (RMSEA) is generally well fit models at values of 0.05 or less, and unusable models at values greater than 0.10 [22].

Pearson coefficients were computed to evaluate the intercorrelation between the sub-scales and total score. The convergent validity of the DISABKIDS scale was assessed based on its correlation with KIDSCREEN-10. We hypothesized that KIDSCREEN-10 would strongly correlate with the Japanese DISABKIDS Chronic Generic Module. We divided the age groups into the 8 to 12 -yearold and the 13 to 18-year-old groups as in the original protocol for developing the DISABKIDS Chronic Generic Module. The discriminant validity was tested examining differences in HrQOL across gender, age, economic status and clinical characteristics.

\section{Results}

\section{Translation and pre-test (focus interviews)}

The translation process was completed in accordance with relevant guidelines, with two forward translations, reconciliation, and one backward translation as well as comparisons between the original and back translation [15]. With regard to difficulties in understanding the items, two children and four parents made comments and suggestions during the focus interviews. For example, a 10-year-old girl mentioned that "lonely" in one question should be written in hiragana (the Japanese cursive syllabary), which is easier for young children to read. A mother of a 10year-old girl stated that she was not sure whether "frustrated" in one item referred to the frustration caused "by the disease itself" or "by symptoms of the disease". Regarding the difficulties of using the response scale, two children and three parents made comments and suggestions. For example, a 15-yearold boy felt that there was a mismatch between some of the questions and response options. Hiragana was added to the term "lonely" as a help to read the latter for young children. We found that there was no need to omit any of the items from the scales or to add new concepts pertaining to HRQOL. 


\section{Field test}

\section{Description of sample}

Table 1 shows the descriptive statistics of the study sample including the number of socio-demographic and clinical variables. A total of 123 children with a chronic condition and 123 parents/caregivers completed the test and retest versions. The age of the children ranged from 8 to 18 years with $51.2 \%$ aged $8-12$ years and $48.8 \%$ aged 13-18 years. The mean age of the parents was 45 years. More than half of the children had allergies, and a quarter had an endocrine disease.

\section{Item analysis and reliability}

The distribution characteristic of the scores for the child- and parent-reported versions are given in Table 2. Floor effects were rare while moderate ceiling effects were observed in three out of six dimensions (Social exclusion, Physical, and Treatment). The internal consistency reliabilities ranged from $r=0.92$ (child-reported version) to $r=0.95$ (parent-reported version). The Guttman split-half reliability reached a coefficient of $r=0.84$ for the child-reported version and $r=0.85$ for the parent-reported version. High levels of agreement between the child and parent reports were observed for both sub-scales ( $\mathrm{ICC}=0.64-0.74$ ) and the total scores $(\mathrm{ICC}=0.77)$. A high test-retest reliability was found across two time points for children (ICC for total score $=0.90, p<0.001$ ), adolescents (ICC for total score $=0.94$, $\mathrm{p}<0.001$ ), and parents (ICC for total score $=0.96-0.97$, $\mathrm{p}<0.001$ ) as shown in Table 3. The mean values, standard deviations, item-subtotal correlations and Cronbach's alpha coefficients for all the 37 items are presented in Additional file 1. Item 6, 19 and 32 for child report had item-subtotal correlations lower than 0.3 , and the deletion of these three items increased the Cronbach's alpha of the subscales at least 0.02 . Item 6, 19 and 32 for child data were dropped for the following analysis.

\section{Confirmatory factor analysis}

The summary of CFA was shown in Additional file 2. The original 12-item Mental domain for the child reported data (Model 0) had low goodness of fit values: $\mathrm{GFI}=0.874, \mathrm{CFI}=0.924$, and $\mathrm{RMSEA}=0.074$. After deletion of Item 6 and 19, the 10-item Mental domain (Model 1) had also low goodness of fit values: $\mathrm{GFI}=0.894, \quad \mathrm{CFI}=0.942$, and $\mathrm{RMSEA}=0.078$. We therefore added the error covariance to the 10-item Mental domain model (Model 2) by using modification indices in Amos version 21.0, and the goodness of fit improved to $\mathrm{GFI}=0.933, \mathrm{CFI}=0.992$, and RMSEA $=0.030$. The Social domain (Model 0) had low goodness of fit values: $\mathrm{GFI}=0.871, \mathrm{CFI}=0.877$,

Table 1 Socio-demographic and clinical characteristics of the sample

\begin{tabular}{|c|c|c|}
\hline & Children/adolescents $(N=123)$ & Parents/caregivers $(\mathrm{N}=123)$ \\
\hline Age years, Mean (SD) & $12.3(3.1)$ & $45.0(5.5)$ \\
\hline \multicolumn{3}{|l|}{ Age group, n (\%) } \\
\hline Children (8-12 years) & $63(51.2)$ & \\
\hline Adolescents (13-18 years) & $60(48.8)$ & \\
\hline \multicolumn{3}{|l|}{ Gender } \\
\hline Male & $66(53.7)$ & $16(13.0)$ \\
\hline Female & $57(46.3)$ & $103(83.7)$ \\
\hline Unanswered & & $4(3.3)$ \\
\hline Marital status: married, n (\%) & & $111(90.2)$ \\
\hline \multicolumn{3}{|c|}{ Economic status (living condition), n (\%) } \\
\hline Very comfortable & & $6(4.9)$ \\
\hline Somewhat comfortable & & $43(35)$ \\
\hline Somewhat difficult & & $60(48.8)$ \\
\hline Very difficult & & 11(8.9) \\
\hline Unanswered & & $3(2.4)$ \\
\hline \multicolumn{3}{|l|}{ Clinical characteristics, n (\%) } \\
\hline Allergies & $70(56.9)$ & \\
\hline Endocrine Disease & $25(20.3)$ & \\
\hline Circulatory disease & $13(10.6)$ & \\
\hline Kidney disease & $11(8.9)$ & \\
\hline Collagen Disease & $4(3.3)$ & \\
\hline
\end{tabular}


Table 2 Psychometric properties for the total score of the Japanese DISABKIDS Chronic generic module (self-report version / parent version)

\begin{tabular}{llllllllllll}
\hline & Domain & Facet & $N$ & Mean & SD & \%floor & \%ceiling & Skewness & Cronbach a & Split-half & ICC \\
\hline DISABKIDS & Mental & Independence & $123 / 122$ & $73.1 / 70.6$ & $16.9 / 18.2$ & $0.0 / 0.0$ & $3.3 / 6.6$ & $-0.7 /-0.5$ & $0.74 / 0.86$ & $0.74 / 0.81$ & $0.71 /-$ \\
& & Emotion & $123 / 123$ & $74.8 / 66.3$ & $19.4 / 20.4$ & $0.0 / 0.8$ & $8.1 / 4.9$ & $-0.7 /-0.7$ & $0.82 / 0.92$ & $0.84 / 0.91$ & $0.70 /-$ \\
& \multirow{2}{*}{ Social } & Social inclusion & $123 / 122$ & $73.3 / 72.2$ & $20 / 18.5$ & $0.0 / 0.0$ & $9.8 / 8.2$ & $-1.0 /-0.6$ & $0.78 / 0.80$ & $0.81 / 0.86$ & $0.70 /-$ \\
& & Social exclusion & $122 / 123$ & $81.2 / 74.9$ & $18.1 / 19.4$ & $0.0 / 0.0$ & $20.3 / 11.4$ & $-1.3 /-0.8$ & $0.75 / 0.87$ & $0.71 / 0.83$ & $0.74 /-$ \\
& \multirow{2}{*}{ Physical } & Physical & $121 / 123$ & $73.1 / 67.4$ & $21.8 / 20.8$ & $0.0 / 0.0$ & $10.7 / 5.7$ & $-0.8 /-0.5$ & $0.79 / 0.86$ & $0.75 / 0.85$ & $0.73 /-$ \\
& & Treatment & $110 / 113$ & $74.9 / 62.3$ & $20.7 / 21.7$ & $0.0 / 0.0$ & $18.2 / 4.4$ & $-0.6 /-0.4$ & $0.77 / 0.88$ & $0.68 / 0.87$ & $0.64 /-$ \\
\multirow{2}{*}{ Total score } & & $123 / 123$ & $75.1 / 70.2$ & $16 / 16.2$ & - & - & $-1.1 /-0.6$ & $0.92 / 0.95$ & $0.84 / 0.85$ & $0.77 /-$ \\
\hline
\end{tabular}

ICC: Infraclass correlation coefficients (ICC) between self-report version and proxy-report version of the Japanese DISABKIDS measure

and RMSEA $=0.090$. The error covariance correction model for Social domain (Model 1) had goodness of fit values with $\mathrm{GFI}=0.902$; $\mathrm{CFI}=0.956$; and $\mathrm{RMSEA}=0.055$. The original 12-item Physical domain (Model 0) had values with $\mathrm{GFI}=0.892 ; \mathrm{CFI}=0.941$; and $\mathrm{RMSEA}=0.063$. After deletion of Item 32, the 11-item Physical domain (Model 1) had values with $\mathrm{GFI}=0.896$; $\mathrm{CFI}=0.936$; and RMSEA $=0.073$. The 11-item Physical domain added the error covariance (Model 2) improved values with $\mathrm{GFI}=0$. 916; $\mathrm{CFI}=0.977 ;$ and $\mathrm{RMSEA}=0.044$. The Mental domain for the proxy reported data (Model 0) had values with GFI $=0.856$; $\mathrm{CFI}=0.935$; and $\mathrm{RMSEA}=0.096$. The Mental domain model with error covariance (Model 1) improved values with $\mathrm{GFI}=0.909 ; \quad \mathrm{CFI}=0.984$; and RMSEA $=0.049$. The Social domain (Model 0) had low goodness of fit values with $\mathrm{GFI}=0.824 ; \mathrm{CFI}=0.875$; and RMSEA $=0.124$. The Social domain model with error covariance (Model 1) had acceptable fit of GFI $=0.884$; $\mathrm{CFI}=0.953$; and RMSEA $=0.077$. The Physical domain (Model 0) had low goodness of fit values with GFI = 0.824; $\mathrm{CFI}=0.887$; and $\mathrm{RMSEA}=0.116$. The Physical domain model with error covariance (Model 1) had an acceptable fit of $\mathrm{GFI}=0.870 ; \mathrm{CFI}=0.931$; and $\mathrm{RMSEA}=0.093$.

\section{Intercorrelations between sub-scales and total score}

Table 4 shows moderate to strong positive correlations among the sub-scales and between the subscales and total scores except for the Treatment sub-scale, which correlated weakly and/or negatively with the remaining sub-scales. No difference was observed in the correlations when the scores of 0 and 100 were excluded from the analysis (see Additional file 3).

\section{Criterion and discriminant validity}

A significant and positive correlation was found between the total score and sub-scale of the DISABKIDS-37 child-reported version, and the total score of the childreported KIDSCREEN-10, except for a low association between the Treatment sub-scale and KIDSCREEN-10 in adolescents $(r=0.08, p=0.544)$. Statistically significant associations were also observed between the total score and sub-scale of the parent-reported version of DISABKIDS-37 and the parent-reported version of KIDSCREEN-10, supporting convergent validity (see Table 5). No difference was observed in the correlation coefficients when 0 and 100 scores were excluded from the analysis (see Additional file 4).

Comparisons of the dimension scores for self-report version according to gender, age group, economic status and clinical characteristics were shown in Table 6 . There was no difference in HRQOL in gender and clinical characteristics. Older adolescents reported lower emotional and physical well-being than younger children. Children belonging to families with lower level of economic status were found to have worse HRQOL in independent, emotion and social inclusion dimensions than

Table 3 Test-retest reliability correlation (self-report version / parent version)

\begin{tabular}{|c|c|c|c|c|c|c|}
\hline & \multirow[t]{2}{*}{ Domain } & \multirow[t]{2}{*}{ Facet } & \multicolumn{2}{|c|}{ Children $(n=63)$} & \multicolumn{2}{|c|}{ Adolescents $(n=60)$} \\
\hline & & & Pearson $r$ & ICC & Pearson $r$ & ICC \\
\hline \multirow[t]{6}{*}{ DISABKIDS } & Mental & Independence & $0.69 / 0.78$ & $0.81 / 0.87$ & $0.83 / 0.81$ & $0.90 / 0.89$ \\
\hline & & Emotion & $0.65 / 0.83$ & $0.78 / 0.90$ & $0.82 / 0.86$ & $0.90 / 0.92$ \\
\hline & Social & Social inclusion & $0.79 / 0.88$ & $0.88 / 0.93$ & $0.83 / 0.92$ & $0.91 / 0.96$ \\
\hline & & Social exclusion & $0.75 / 0.89$ & $0.85 / 0.94$ & $0.74 / 0.82$ & $0.85 / 0.90$ \\
\hline & Physical & Physical limitation & $0.47 / 0.84$ & $0.64 / 0.90$ & $0.84 / 0.81$ & $0.91 / 0.89$ \\
\hline & & Treatment & $0.68 / 0.87$ & $0.81 / 0.93$ & $0.74 / 0.82$ & $0.85 / 0.93$ \\
\hline Total score & & & $0.83 / 0.94$ & 0.90/0.97 & $0.89 / 0.93$ & $0.94 / 0.96$ \\
\hline
\end{tabular}


Table 4 Intercorrelation (Pearson r) between total score and sub-scales of the self-report version and parent version

\begin{tabular}{|c|c|c|c|c|c|c|}
\hline \multicolumn{7}{|c|}{ Self-report/ proxy-report } \\
\hline & Independence & Emotion & Social inclusion & Social exclusion & Physical limitation & Treatment \\
\hline \multicolumn{7}{|l|}{ Children $(n=63)$} \\
\hline Emotion & $0.61^{* *} / 0.61^{* *}$ & & & & & \\
\hline Social inclusion & $0.60^{* *} / 0.57^{* *}$ & $0.57^{* *} / 0.28^{*}$ & & & & \\
\hline Social exclusion & $0.65^{* *} / 0.59^{* *}$ & $0.70^{* *} / 0.69^{* *}$ & $0.63^{* *} / 0.42^{* *}$ & & & \\
\hline Limitation & $0.56^{* *} / 0.61^{* *}$ & $0.71^{* *} / 0.71^{* *}$ & $0.60^{* *} / 0.39^{* *}$ & $0.73^{* *} / 0.76^{* *}$ & & \\
\hline Treatment & $0.08 / 0.05$ & $0.34^{*} / 0.53^{* *}$ & $-0.06 /-0.06$ & $-0.01 / 0.45^{* *}$ & $0.16 / 0.39^{* *}$ & \\
\hline Total score & $0.77^{* *} / 0.75^{* *}$ & $0.89^{* *} / 0.87^{* *}$ & $0.78^{* *} / 0.55^{* *}$ & $0.84^{* *} / 0.86^{* *}$ & $0.87^{* *} / 0.86^{* *}$ & $0.34^{*} / 0.59^{* *}$ \\
\hline \multicolumn{7}{|l|}{ Adolescents $(n=60)$} \\
\hline Emotion & $0.71^{* *} / 0.74^{* *}$ & & & & & \\
\hline Social inclusion & $0.58^{* *} / 0.54^{* *}$ & $0.485^{* *} / 0.31^{*}$ & & & & \\
\hline Social exclusion & $0.58^{* *} / 0.61^{* *}$ & $0.64^{* *} / 0.62^{* *}$ & $0.49^{* *} / 0.63^{* *}$ & & & \\
\hline Limitation & $0.62^{* *} / 0.71^{* *}$ & $0.66^{* *} / 0.80^{* *}$ & $0.60^{* *} / 0.54^{* *}$ & $0.68^{* *} / 0.77^{* *}$ & & \\
\hline Treatment & $-0.04 / 0.47^{* *}$ & $0.10 / 0.65^{* *}$ & $0.09 / 0.16$ & $0.19 / 0.33^{*}$ & $0.17 / 0.40^{* *}$ & \\
\hline Total score & $0.79^{* *} / 0.85^{* *}$ & $0.81^{* *} / 0.88^{* *}$ & $0.73^{* *} / 0.66^{* *}$ & $0.79^{* *} / 0.83^{* *}$ & $0.88^{* *} / 0.90^{* *}$ & $0.32 * / 0.65^{* *}$ \\
\hline \multicolumn{7}{|c|}{ Cross-cultural sample ${ }^{a}$} \\
\hline Emotion & $0.52 / 0.55$ & & & & & \\
\hline Social inclusion & $0.57 / 0.60$ & $0.40 / 0.49$ & & & & \\
\hline Social exclusion & $0.49 / 0.55$ & $0.57 / 0.68$ & $0.46 / 0.55$ & & & \\
\hline Limitation & $0.41 / 0.42$ & $0.62 / 0.64$ & $0.42 / 0.34$ & $0.36 / 0.42$ & & \\
\hline Treatment & $0.31 / 0.33$ & $0.60 / 0.55$ & $0.24 / 0.30$ & $0.44 / 0.49$ & $0.37 / 0.36$ & \\
\hline Total score & $0.72 / 0.73$ & 0.86/0.88 & $0.67 / 0.70$ & $0.73 / 0.81$ & $0.72 / 0.71$ & $0.71 / 0.70$ \\
\hline
\end{tabular}

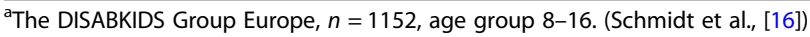

${ }^{*} P<0.05,{ }^{*} P<0.01$

children belonging to families with higher level of economic status.

\section{Discussion}

The present study examined the psychometric properties of the DISABKIDS Chronic Generic Module for assessing HRQOL in Japanese children and adolescents with a chronic condition using both child- and parentreported versions. Following the DISABKIDS group guidelines, we translated items and responses and examined their content through focus interviews. Our results revealed good internal consistency, split-half reliability,

Table 5 Correlation coefficients (Pearson r) for total score and sub-scales of the self-report and parent versions with KIDSCREEN (selfreport and parent versions)

\begin{tabular}{|c|c|c|c|c|c|c|c|c|}
\hline & & Independence & Emotion & $\begin{array}{l}\text { Social } \\
\text { inclusion }\end{array}$ & $\begin{array}{l}\text { Social } \\
\text { exclusion }\end{array}$ & $\begin{array}{l}\text { Physical } \\
\text { limitation }\end{array}$ & Treatment & $\begin{array}{l}\text { Total } \\
\text { score }\end{array}$ \\
\hline \multirow[t]{7}{*}{ KIDSCREEN } & Children & & & & & & & \\
\hline & Self-report version & $0.44^{* *}$ & $0.54^{\#}$ & $0.48^{\#}$ & $0.38^{* *}$ & $0.37^{* *}$ & $0.41^{* *}$ & $0.60^{\#}$ \\
\hline & Parent version & $0.55^{\#}$ & $0.55^{\#}$ & $0.59^{\#}$ & $0.56^{\#}$ & $0.52^{\#}$ & $0.39^{* *}$ & $0.68^{\#}$ \\
\hline & Adolescents & & & & & & & \\
\hline & Self-report version & $0.65^{\#}$ & $0.50^{\#}$ & $0.65^{\#}$ & $0.60^{\#}$ & $0.61^{\#}$ & 0.08 & $0.71^{\#}$ \\
\hline & Parent version & $0.67^{\#}$ & $0.48^{\#}$ & $0.58^{\#}$ & $0.54^{\#}$ & $0.61^{\#}$ & $0.41^{* *}$ & $0.68^{\#}$ \\
\hline & $\begin{array}{l}\text { Cross-cultural sample (self/ } \\
\text { proxy) }\end{array}$ & $0.70 / 0.79$ & $\begin{array}{l}0.84 / \\
0.92\end{array}$ & $0.68 / 0.74$ & $0.77 / 0.83$ & 0.70/0.79 & 0.80/0.85 & $0.91 / 0.94$ \\
\hline
\end{tabular}

${ }^{a}$ The DISABKIDS Group Europe, $n=1152$, age group 8-16 (Schmidt et al., [16]) ${ }^{*} p<0.05,{ }^{* *} p<0.01,{ }^{\#} p<0.001$ 
Table 6 Comparisons of the dimension scores for self-report version according to gender, age group, economic status and clinical characteristics

\begin{tabular}{|c|c|c|c|c|c|c|c|}
\hline & Independence & Emotion & Social inclusion & Social exclusion & Physical limitation & Treatment & Total score \\
\hline \multicolumn{8}{|l|}{ Gender } \\
\hline Boys & $74.2 \pm 18.9$ & $75.1 \pm 21.3$ & $73.5 \pm 20.0$ & $80.4 \pm 18.7$ & $74.1 \pm 20.7$ & $74.3 \pm 24.9$ & $74.5 \pm 15.2$ \\
\hline Girls & $75.5 \pm 17.9$ & $78.1 \pm 19.7$ & $74.3 \pm 17.9$ & $82.1 \pm 17.5$ & $71.8 \pm 23.1$ & $71.9 \pm 20.9$ & $74.8 \pm 15.6$ \\
\hline$P$ values & 0.68 & 0.42 & 0.81 & 0.62 & 0.55 & 0.59 & 0.92 \\
\hline \multicolumn{8}{|l|}{ Age group } \\
\hline Children & $77.8 \pm 17.5$ & $81.2 \pm 19.3$ & $74.8 \pm 18.2$ & $82.3 \pm 19.8$ & $78.2 \pm 20.7$ & $76.4 \pm 22.3$ & $77.8 \pm 15.1$ \\
\hline Adolescents & $71.6 \pm 19.0$ & $71.5 \pm 20.9$ & $72.9 \pm 19.8$ & $79.9 \pm 16.3$ & $67.8 \pm 21.8$ & $70.0 \pm 23.3$ & $71.5 \pm 15.0$ \\
\hline$P$ values & 0.06 & 0.01 & 0.57 & 0.46 & 0.01 & 0.14 & 0.03 \\
\hline \multicolumn{8}{|l|}{ Economic status $^{a}$} \\
\hline Comfortable & $79.6 \pm 15.8$ & $81.8 \pm 16.3$ & $77.5 \pm 14.7$ & $84.3 \pm 16.5$ & $75.0 \pm 18.3$ & $74.6 \pm 21.8$ & $78.4 \pm 12.4$ \\
\hline Difficult & $71.3 \pm 19.4$ & $72.5 \pm 22.5$ & $71.1 \pm 21.2$ & $78.8 \pm 18.9$ & $71.6 \pm 23.9$ & $72.2 \pm 23.7$ & $72.3 \pm 16.5$ \\
\hline$P$ values & 0.01 & 0.01 & 0.05 & 0.09 & 0.38 & 0.60 & 0.04 \\
\hline \multicolumn{8}{|l|}{ Clinical characteristics $^{\mathrm{b}}$} \\
\hline Allergies & $77.0 \pm 18.4$ & $79.3 \pm 20.0$ & $75.6 \pm 19.0$ & $80.8 \pm 19.1$ & $76.2 \pm 21.2$ & $74.8 \pm 21.3$ & $77.4 \pm 15.2$ \\
\hline Endocrine Disease & $68.2 \pm 20.6$ & $69.0 \pm 21.9$ & $70.3 \pm 20.2$ & $76.0 \pm 18.8$ & $65.0 \pm 23.8$ & $66.3 \pm 27.0$ & $68.8 \pm 15.8$ \\
\hline Others & $75.2 \pm 15.4$ & $75.9 \pm 19.9$ & $72.7 \pm 17.8$ & $87.0 \pm 13.0$ & $72.6 \pm 20.1$ & $75.6 \pm 23.4$ & $71.7 \pm 13.5$ \\
\hline$P$ values & 0.12 & 0.10 & 0.46 & 0.09 & 0.09 & 0.28 & 0.06 \\
\hline
\end{tabular}

Dimension scores are reported as mean standard deviation

a Economic status is recorded into two categories: Comfortable includes "Very comfortable" and "Somewhat comfortable". Difficult includes "Somewhat difficult" and "Very difficult"

b $P$ values: significance level of analysis of variance test. "Others" include Circulatory disease, Kidney disease, and Collagen Disease

and test-retest reliability for the DISABKIDS Chronic Generic Module. Three items for child report data had item-subtotal correlations lower than 0.3 , and the deletion of these three items increased the Cronbach's alpha of the subscales at least 0.02 . The CFA revealed that the modified models for all domains were better fit than the original 37 item scale model for both self-report and proxy-report. Good convergent validity of this scale with both the child-reported and parent-reported versions of KIDSCREEN-10 was observed. The results indicated that the modified models of Japanese version of DISABKIDS Chronic Generic Module are psychometrically acceptable for assessing the HRQOL of Japanese children and adolescents with a chronic condition.

Moderate ceiling effects in the Social exclusion, Physical, and Treatment dimensions were observed mainly in the self-report. This finding was not unique to our sample, as similar ceiling effects have been reported in a European study [13] as well as for other HRQOL scales designed for children and adolescents with a chronic condition [23]. While there was agreement between child-reported and parent-reported scores, the child's rating of quality of life was higher than that of their parent for all facets as observed in the previous studies $[16,24]$.

Item 6, 19 and 32 for child report data had itemsubtotal correlations lower than 0.3 , and the deletion of these three items increased the Cronbach's alpha of the subscales at least 0.02 . This indicated that these three items may need to be rephrased. We suspected that the term "things" in item 6 "Are you able to do things without your parents?" was not specific and therefore it might be difficult to answer the question. Item 19 "Does it bother you that your life has to be planned?" and item 32 "Does having to get help with medication from others bother you?" contained the common term "bother", which might have made it difficult to interpret.

The Japanese version of the DISABKIDS 37 showed weakness in terms of structural models. Translation or cultural aspects cannot be eliminated as a factor of error variation. However, the good to high level of internal consistency reliabilities indicated that reasons may lie elsewhere. Although a suitable structure for this measure verified in the cross-cultural validation study, there were some restrictions in several countries [16]. Therefore, some aspects of model unfitness in this study could be due to instabilities or inadequacies in the conceptual foundation of the construct itself.

We observed a moderate to strong, positive association among the DISABKIDS sub-scales and between the subscales and total scores [16] except for the Treatment sub-scale, which correlated weakly with the remaining subscales. The validation studies for the Portuguese version of DISABKIDS also found a weak association between the 
Treatment sub-scale and the other sub-scales [25]. On the other hand, the correlation coefficients between the Treatment sub-scale and the other sub-scales in children and adolescents were lower than those in their parent, which was not previously observed in other populations using the same scales. Cultural factors may have caused the divergence, i.e., in Japan children may tend to accept their condition and treatment so that the burden imposed by these may not impair other aspects of their life. Convergent validity was inferred from a statistically significant correlation between child-reported DISABKIDS-37 and KIDSCREEN10. On a descriptive level, low emotional well-being was found in adolescents and in children belonging families with relatively low economic status. These findings have been also observed in previous studies [13].

The limitations of our study include the selectivity of the sample in terms of clinical conditions (mainly allergies and endocrine diseases) and its monocentric design (only one facility in Japan). A larger sample of different clinical conditions from a variety of facilities may have yielded different psychometric properties. Also, because of the cross-sectional study design, it was not possible to examine the sensitivity of the instrument for detecting changes in the children's health condition. These challenges will need to be addressed in future studies.

This study validates the utility of the modified models of DISABKIDS Chronic Generic Module for assessing the HRQOL of Japanese children and adolescents with a chronic condition. It is particularly important not only for the children themselves but also for health professionals, teachers, parents, and other caregivers to understand the importance of HRQOL over the course of treatment. Moreover, with the many language versions available, DISABKIDS may be used in future, crosscultural research comparing HRQOL.

\section{Conclusion}

The findings of this study demonstrated acceptable psychometric performance of the modified models of DISABKIDS-37 when used with Japanese children and adolescents with a chronic condition. Further research in larger samples is needed to determine whether the same factors will be extracted and their validity can be verified. The HRQOL assessment used for this particular population may not only be of value in clinical trials of new therapies, but will facilitate communication between patients and health professionals, identify healthcare needs, and support life at home and school.

\section{Additional files}

Additional file 1: Mean, SD, Correlations, and Cronbach a of Items. (PDF $121 \mathrm{~kb}$ )
Additional file 2: Summary of Confirmatory Factor Analysis. (PDF $10 \mathrm{~kb}$ ) Additional file 3: Intercorrelation (Pearson r) between total score and sub-scales for excluding 0 and 100 scores. (PDF $78 \mathrm{~kb}$ )

Additional file 4: Correlation coefficients (Pearson r) for total score and sub-scales with the KIDSCREEN for excluding 0 and 100 scores. (PDF $97 \mathrm{~kb})$

\section{Abbreviations}

HRQOL: Health-related quality of life; ICC: Intraclass correlation coefficient: PRO: Patient-reported outcome; SD: Standard deviation; SPSS: Statistical package for social sciences

\section{Acknowledgements}

The authors wish to thank Dr. Katsuhiro Arai, Dr. Shuichi Ito, Dr. Yukihiro Oya and Dr. Reiko Horikawa (National Center for Child Health and Development), and all the children and their families who generously participated in this study. We also thank Dr. Kayo Onishi, Ms. Miho Tayama, Ms. Hitomi Motegi and Ms. Kie Imai for data collection, and Mr. James R. Valera for his editorial support.

\section{Funding}

This study was supported by a Health and Labour Sciences Research Grant in FY2014 (H25-Jisedai-Ippan-004) and FY2017 (H28-Nanchitou-Shitei-004), from the Ministry of Health, Labour and Welfare of Japan. The funder had no role in the study design, data collection and analysis, decision to publish or preparation of the manuscript.

\section{Availability of data and materials}

Data are available from the authors upon reasonable request and with permission of the European DISABKIDS Group.

\section{Authors' contributions}

HS contributed to the study design and the process of instrument translation, managed data collection, carried out the data analysis, and wrote the manuscript. NK contributed to the study design and the process of instrument translation. NM and RM contributed to the process of instrument translation. URS and MB provided supervision during the instrument translation and adaptation phase and also reviewed the manuscript. All authors approved the final version of the manuscript.

\section{Competing interest}

The authors declare that they have no competing interests.

\section{Ethics approval and consent to participate}

In both the pre-test and field-test phases verbal consent was obtained from children aged 8 to 18 years. Written consent was requested from children older than 16 years or those who had the maturity to understand the relevant conditions and their parents. This study was approved by the Ethical Review Board of the National Center for Child Health and Development in Tokyo, Japan (Reference No. 734 and No. 750).

\section{Publisher's Note}

Springer Nature remains neutral with regard to jurisdictional claims in published maps and institutional affiliations.

\section{Author details}

${ }^{1}$ Medical Support Center for Japan Environment and Children's Study (JECS), National Center for Child Health and Development, 2-10-1 Okura, Setagaya, Tokyo 157-8535, Japan. ${ }^{2}$ Division of Bioethics, National Center for Child Health and Development, Tokyo, Japan. ${ }^{3}$ Department of Social Medicine, National Center for Child Health and Development, Tokyo, Japan. ${ }^{4}$ Department of Health Policy, National Center for Child Health and Development, Tokyo, Japan. ${ }^{5}$ Department of Child and Adolescent Psychiatry, Psychotherapy, and Psychosomatics, University Medical Center Hamburg-Eppendorf, Hamburg, Germany. ${ }^{6}$ Department of Medical Psychology, University Medical Center Hamburg-Eppendorf, Hamburg, Germany. 
Received: 2 October 2017 Accepted: 23 April 2018

Published online: 02 May 2018

\section{References}

1. 2016 Annual Report. Information Center for Specific Pediatric Chronic Disease, Japan [https://www.shouman.jp/research/pdf/20_28/28_01.pdf]. Accessed July 2017

2. 2013-2015 Annual report. Information Center for Specific Pediatric Chronic Disease, Japan [https://www.shouman.jp/research/pdf/19_2527/2527_00. pdf]. Accessed July 2017.

3. Uchida K, Kawamata A, Hashimoto K, Inoue M, Otake K, Koike Y, Matsushita K, Fujikawa H, Okita Y, Araki T. Self-reported assessment of health-related quality of life in children who underwent restorative proctocolectomy with ileal Jpouch anal anastomosis for ulcerative colitis. Pediatr Surg Int. 2013;29:287-91.

4. Takahashi R, Ogawa M, Osada H. Quality of life of SGA children with short stature receiving GH treatment in Japan. Pediatr Endocrinol Rev. 2017;14:222.

5. Okano Y, Kobayashi K, Ihara K, Ito T, Yoshino M, Watanabe Y, Kaji S, Ohura T, Nagao M, Noguchi A. Fatigue and quality of life in citrin deficiency during adaptation and compensation stage. Mol Genet Metab. 2013;109:9-13.

6. Wakimizu R, Hiraga N, Furuya K, Fukushima T, Tsuchida M, Koike K, Yamamoto T. Depression and health-related quality of life after discharge and associated factors in childhood cancer patients in Japan. Bioscience trends. 2011:5:264-72.

7. Kojima N, Ohya Y, Futamura M, Akashi M, Odajima H, Adachi Y, Kobayashi F, Akasawa A. Exercise-induced asthma is associated with impaired quality of life among children with asthma in Japan. Allergol Int. 2009:58:187-92.

8. Riley AW, Forrest CB, Rebok GW, Starfield B, Green BF, Robertson JA, Friello $P$. The child report form of the CHIP-child edition: reliability and validity. Med Care. 2004;42:221-31.

9. Kobayashi K, Kamibeppu K. Measuring quality of life in Japanese children: development of the Japanese version of PedsQL. Pediatr Int. 2010;52:80-8.

10. Nezu S, Iwasaka H, Saeki K, Ishizuka R, Goma H, Okamoto N, Makino H, Tanimura M, Yoshizaki K, Obayashi K. Reliability and validity of the Japanese version of the KIDSCREEN-52 health-related quality of life questionnaire for children/adolescents and parents/proxies. Environ Health Prev Med. 2015;20: 44-52.

11. Nezu S, Iwasaka H, Saeki K, Obayashi K, Ishizuka R, Goma H, Furuichi Y, Kurumatani N. Reliability and validity of Japanese versions of KIDSCREEN-27 and KIDSCREEN-10 questionnaires. Environ Health Prev Med. 2016:21:154-63.

12. Nemoto Y. Japanese version of the kiddy-KINDLR. Jpn Soc Health Sci Child. 2012;13:47-51

13. Simeoni M-C, Schmidt S, Muehlan H, Debensason D, Bullinger M. Field testing of a European quality of life instrument for children and adolescents with chronic conditions: the 37-item DISABKIDS chronic generic module. Qual Life Res. 2007;16:881-93.

14. Sasaki H, Kakee N, Morisaki N, Mori R, Ravens-Sieberer U, Bullinger M Assessing health-related quality of life in young Japanese children with chronic conditions: preliminary validation of the DISABKIDS smiley measure. BMC Pediatr. 2017;17:100.

15. DISABKIDS Group: DISABKIDS translation \& validation procedure-guidelines and documentation form [http://www.disabkids.org/app/download/ 6469841080/Translation_Procedure.pdf?t=1381846711]. Accessed Aug 2013.

16. Schmidt S, Petersen C, Mühlan H, Simeoni MC, Debensason D, Thyen U, Müller-Godeffroy E, Vidalis A, Tsanakas J, Hatziagorou E. The DISABKIDS questionnaires quality of life questionnaires for children with chronic conditions-handbook-the European DISABKIDS group. Pabst Sci Publishers; 2006.

17. Ravens-Sieberer U, Erhart M, Rajmil L, Herdman M, Auquier P, Bruil J, Power M, Duer W, Abel T, Czemy L, et al. Reliability, construct and criterion validity of the KIDSCREEN-10 score: a short measure for children and adolescents' well-being and health-related quality of life. Qual Life Res. 2010;19:1487-500.

18. Ravens-Sieberer U, Gosch A, Rajmil L, Erhart M, Bruil J, Power M, Duer W, Auquier $P$, Cloetta B, Czemy L, et al. The KIDSCREEN-52 quality of life measure for children and adolescents: psychometric results from a crosscultural survey in 13 European countries. Value Health. 2008:11:645-58.

19. Field A. Discovering statistics using SPSS. In: Wright DB, editor. ISM introducing statistical methods. London: SAGE Publications; 2005.

20. Deyo RA, Diehr P, Patrick DL. Reproducibility and responsiveness of health status measures statistics and strategies for evaluation. Control Clin Trials. 1991;12:S142-58
21. Petersen C, Schmidt S, Power M, Bullinger M. Development and pilottesting of a health-related quality of life chronic generic module for children and adolescents with chronic health conditions: a European perspective. Qual Life Res. 2005;14(4):1065-77.

22. Oshio S. First analysis of covariance structure: pass analysis with Amos (pp 110-111). Tokyo: Tokyotosho; 2008

23. Chan KS, Mangione-Smith R, Burwinkle TM, Rosen M, Varni JW. The PedsQL ${ }^{T M}$. reliability and validity of the short-form generic core scales and asthma module. Med Care. 2005;43:256-65.

24. Chaplin JE, Hallman M, Nilsson NO, Lindblad B. The reliability of the disabled children's quality-of-life questionnaire in Swedish children with diabetes. Acta Paediatr. 2012;101:501-6.

25. Carona C, Crespo C, Silva N, Lopes AF, Canavarro MC, Bullinger M. Examining a developmental approach to health-related quality of life assessment: psychometric analysis of DISABKIDS generic module in a Portuguese sample. Vulnerable Child Youth Stud. 2013:8:243-57.

\section{Ready to submit your research? Choose BMC and benefit from:}

- fast, convenient online submission

- thorough peer review by experienced researchers in your field

- rapid publication on acceptance

- support for research data, including large and complex data types

- gold Open Access which fosters wider collaboration and increased citations

- maximum visibility for your research: over $100 \mathrm{M}$ website views per year

At BMC, research is always in progress.

Learn more biomedcentral.com/submissions 